\title{
Probabilistic Liquefaction Triggering based on the Cone Penetration Test
}

\author{
R. E. S. Moss ${ }^{1}$, R. B. Seed ${ }^{2}$, R. E. Kayen ${ }^{3}$, J. P. Stewart ${ }^{4}$, and K. Tokimatsu ${ }^{5}$ \\ ${ }^{1}$ Project Engineer, Fugro West, Inc., Ventura, CA; email: rmoss@ fugro.com \\ ${ }^{2}$ Prof., Dept. Civil and Environmental Engineering, U.C. Berkeley. \\ ${ }^{3}$ Researcher, US Geological Survey, Menlo Park. \\ ${ }^{4}$ Assoc. Prof., Dept. Civil and Environmental Engineering, U.C. Los Angeles. \\ ${ }^{5}$ Prof., Dept. Civil Engineering and Architecture, Tokyo Institute of Technology.
}

\begin{abstract}
Performance-based earthquake engineering requires a probabilistic treatment of potential failure modes in order to accurately quantify the overall stability of the system. This paper is a summary of the application portions of the probabilistic liquefaction triggering correlations proposed recently proposed by Moss and co-workers. To enable probabilistic treatment of liquefaction triggering, the variables comprising the seismic load and the liquefaction resistance were treated as inherently uncertain. Supporting data from an extensive Cone Penetration Test (CPT)-based liquefaction case history database were used to develop a probabilistic correlation. The methods used to measure the uncertainty of the load and resistance variables, how the interactions of these variables were treated using Bayesian updating, and how reliability analysis was applied to produce curves of equal probability of liquefaction are presented. The normalization for effective overburden stress, the magnitude correlated duration weighting factor, and the non-linear shear mass participation factor used are also discussed.
\end{abstract}

\section{Introduction}

Correlations based on in situ index tests are widely used in engineering practice to estimate the potential for liquefaction triggering. The CPT is a reliable in situ index test that has found widespread use as a tool for measuring resistance of potentially liquefiable layers. CPT-based liquefaction triggering curves have been suggested by previous researchers (e.g., Shibata \& Teparaska, 1988; Seed \& De Alba, 1986; Mitchell \& Tseng, 1990; Stark \& Olson, 1995; Suzuki et al., 1995; Robertson \& Campanella, 1985; Robertson \& Wride, 1998; Toprak et al., 1999; and Juang et al., 2003). For use in performance-based engineering analysis the triggering correlations must be presented in a probabilistic manner.

This paper summarizes the recent CPT-based probabilistic liquefaction triggering correlations proposed in Moss et al. (2004), portions of which have been presented in Seed et al., (2003) and Moss and Seed (2004). The purpose of this research was to provide as unbiased an assessment of liquefaction triggering as possible using a comprehensive worldwide CPT-based liquefaction case history database compiled for this purpose (Moss et al., 2003).

Careful consideration was given to processing the empirical data. The uncertainties associated with the various load and resistance parameters were quantified using different 
statistical techniques. Normalization of the CPT for effective overburden stress was readdressed, applying cavity expansion methods to a previous empirically-based normalization technique.

A Bayesian framework allowed for careful and thorough treatment of all types of uncertainties associated with the vagaries of observed liquefaction/non-liquefaction. This Bayesian framework used structural reliability methods to estimate the probability of liquefaction. The results are curves of equal probability of seismic liquefaction triggering which can be used in performance-based engineering decisions.

\section{Threshold of Liquefaction Triggering}

The threshold of liquefaction triggering, or the liquefaction/non-liquefaction boundary, has traditionally been located deterministically by researchers. Based on the position and spread of the liquefaction and non-liquefaction data points, a curve was drawn showing the best estimate of the threshold of liquefaction triggering. In this study the threshold was located using engineering statistics, Bayesian updating, and reliability methods that were formulated for this particular problem (Cetin et al., 2002; Moss et al., 2003).

Figure 1 is a plot of the liquefaction and non-liquefaction data with error bars showing \pm 1 standard deviation. The resistance is represented by the normalized CPT tip resistance $\left(q_{c, 1}\right)$ in megapascals (MPa). The load is represented by the equivalent uniform cyclic stress ratio $(C S R)$ as calculated using the simplified technique first proposed by Seed and Idriss (1971);

$$
C S R=\frac{\tau_{a v g}}{\sigma^{\prime}{ }_{v}}=0.65 \cdot \frac{a \max }{g} \cdot \frac{\sigma_{v}}{\sigma_{v}^{\prime}} \cdot r_{d}
$$

In the analysis of the sites that comprise the database of the present model, the equivalent uniform cyclic stress ratio was assumed to be the average or mean of a normally distributed random variable, which can rewritten as Equation 2. The variance of CSR can be calculated using Equation 3, where the coefficient of variation $(\delta)$ is the normalized standard deviation, equal to the standard deviation $(\sigma)$ divided by the mean $(\mu)$. Both Equation 2 and 3 are derived using a first-order Taylor series expansions about the mean point, including only the first two terms.

$$
\begin{aligned}
& \mu_{C S R} \cong 0.65 \cdot \frac{\mu_{a \max }}{g} \cdot \frac{\mu_{\sigma_{v}}}{\mu_{\sigma_{v}^{\prime}}} \cdot \mu_{r d} \\
& \delta_{C S R}{ }^{2} \cong \delta_{a \max }{ }^{2}+\delta_{r d}{ }^{2}+\delta_{\sigma_{v}}{ }^{2}+\delta_{\sigma_{v}^{\prime}}{ }^{2}-2 \cdot \rho_{\sigma v} \sigma_{v}^{\prime} \cdot \delta_{\sigma_{v}} \cdot \delta_{\sigma_{v}^{\prime}}
\end{aligned}
$$

Equation 3 indicates that the variance of the cyclic stress ratio $(C S R)$, the dependent variable, is a function of the variance and covariance of the independent variables, maximum ground acceleration $\left(a_{\max }\right)$, total and effective vertical stress $\left(\sigma_{v}\right.$ and $\left.\sigma_{v}{ }^{\prime}\right)$, and nonlinear shear mass participation factor $\left(r_{d}\right)$. In this study all variables were assumed to be normally distributed and statistically independent unless otherwise noted. Total and effective stress are correlated variables, therefore the correlation coefficient term $\left(\rho_{\sigma v \sigma v^{\prime}}\right)$ for these two variables was included. 
Estimating the variance of the all the independent variables was performed using the most appropriate statistical techniques (i.e., for total and effective stress a Taylor-series expansion, for $a_{\max }$ a rational equation based on the quality of the available strong motion data, for moment magnitude a relationship fitted to various reported event magnitudes, and for $r_{d}$ a statistical analysis by Cetin et al., 2004). A thorough discussion of these statistical techniques can be found in Moss et al. (2004).

The variance of the resistance, $q_{c, 1}$ and $R_{f}$, was found by calculating the standard deviation of the tip and sleeve measurements throughout the depth of the critical layer. The critical layer was defined as the layer estimated to be the most eminently liquefiable; the layer that either was observed to have liquefied or thought to be the most susceptible to liquefaction. A thorough discussion of critical layer selection and related issues can be found in Moss et al. (2004). All resistance variables were also assumed to be normally distributed and statistically independent unless otherwise noted.

As seen in Figure 1 the variance of the load tends to be greatest in the high CSR range and the variance of the resistance tends to greatest in the high $\mathrm{q}_{\mathrm{c}, 1}$ range. The region where liquefaction and non-liquefaction data points merge can be thought of as a "mixing" zone. In this zone lies the most likely threshold of liquefaction triggering.

\section{Bayesian Framework}

Thus far the discussion has outlined the data processing of liquefaction/non-liquefaction case histories; the steps for estimating means and standard deviations of the independent and dependent variables. A great deal of time and effort was invested in the data collection and processing because a correlation is only as good as the quality of its data. The next step was to evaluate the processed data as a whole and develop a correlation 
between the load and resistance variables with respect to observed liquefaction/nonliquefaction.

A Bayesian framework using structural reliability methods was used to develop the correlation. A full discussion of the application of Bayesian methods to liquefaction triggering analysis can be found in Cetin et al. (2002), and Moss et al. (2003). In summary; Bayes rule was used as the foundation of the probabilistic analysis, a likelihood function was formulated to describe the observations of liquefaction/nonliquefaction, a limit-state function was formulated to define the liquefaction/nonliquefaction threshold, Bayesian updating was used to determine the distribution of the unknown model parameters in the limit-state function, and component reliability analysis was used to assess the probability of liquefaction based on the limit-state function with the posterior model parameter distributions. This process can be thought of as a regression-type procedure that has been designed to incorporate all forms of parameter uncertainty as well as model uncertainty, thereby producing a "best" estimate of the means and variances of liquefaction triggering.

\section{Data Screening, Adjustment, and Correction}

A thorough and proper treatment of the data required different methods of screening, adjustment, and correction. A revised screening procedure, akin to the "Modified Chinese Criteria" (Wang, 1979; Seed and Idriss, 1982) was used. Presented are corrections to normalize the resistance measurements for effective overburden stress and corrections to CSR for the duration of strong ground shaking. Also discussed is the nonlinear shear mass participation factor. All these screening, adjustment, and correction methods were readdressed (with respect to previous studies) to provide an unbiased estimate of liquefaction triggering for performance-based decisions.

\section{Screening}

Certain soil types are not susceptible to liquefaction in what we term "classic" free-field liquefaction, but may deform via cyclic softening. These soils can exhibit surface manifestations that appear quite similar to what is observed in "classic" liquefaction, such as lateral spreading, and building tilting, punching, and settlement. However, it has been found (Sancio et al., 2003) that the failure is primarily a function of undrained strength and asymmetrical driving shear stress $\left(K_{\alpha}\right)$ imposed by a building or sloping ground. These soils tend to have a high percentage of fines, and these fines tend to behave in a plastic manner. Several cases like this were observed following the 2001 Kocaeli, Turkey Earthquake, and the 2001 Chi-Chi, Taiwan Earthquake, and were evaluated during the compilation of the CPT-based case history database (Moss et al., 2003). Since the limit-state function in this study was based on "classic" free-field liquefaction, it was not appropriate to include these cases in the analysis.

The criteria for screening these cases were based on research of fines content and plasticity in relation to liquefaction susceptibility (Andrews \& Martin, 2000; Andrianopoulos et al., 2001; Guo \& Prakash, 1999; Perlea, 2000; Polito, 2001; Sancio et 
al., 2003; Yamamuro \& Lade, 1998, Youd \& Gilstrap, 1999). Zone A, shown graphically in Figure 2, was the envelope of potentially liquefiable materials used in this study. Using only Zone $\mathrm{A}$ is a conservative approach, that eliminated some potentially liquefiable materials in Zone B that require further laboratory testing. Zone A materials, however, exhibit behavior consistent with "classic" free-field liquefaction.

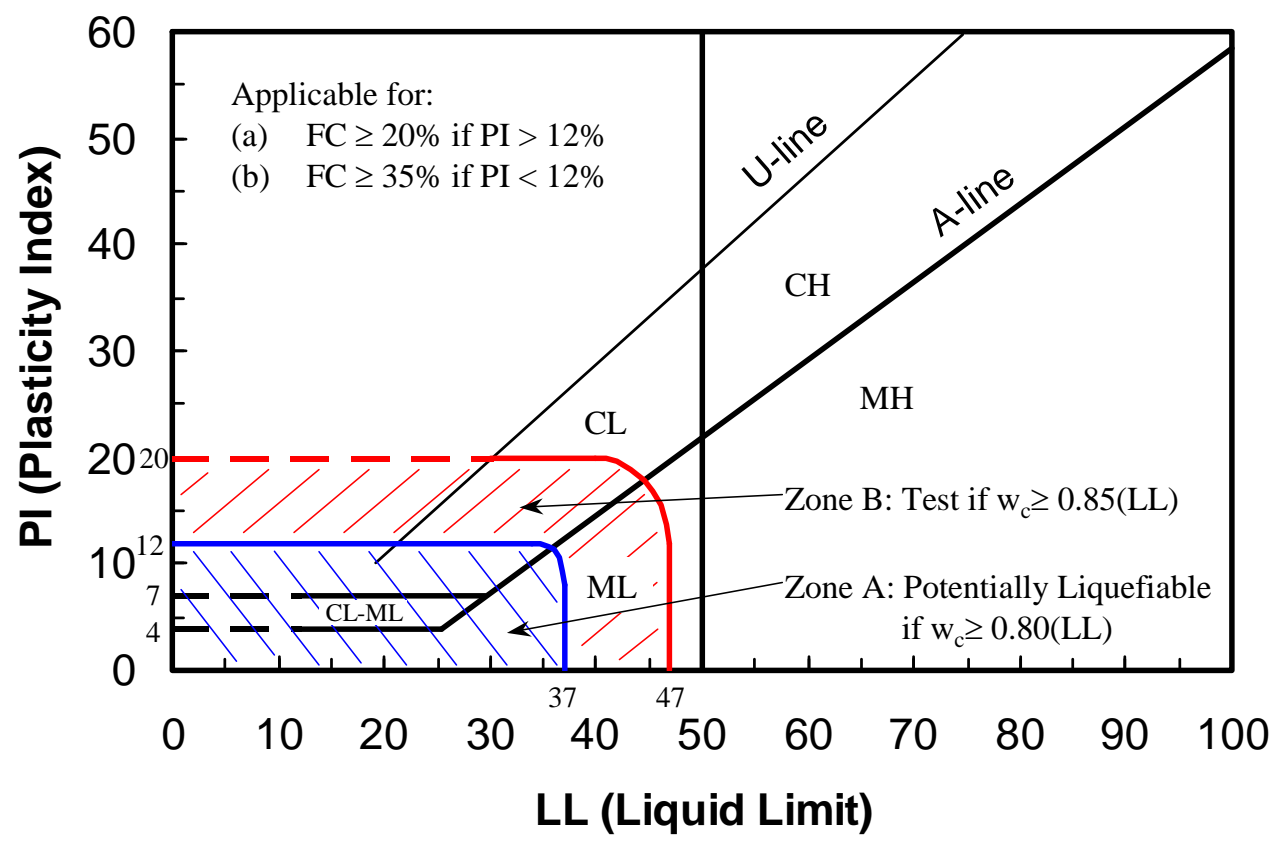

Figure 2. Modified "Atterberg" chart showing recommendations regarding the assessment of soil types considered liquefiable, from Seed et al., (2003).

\section{Normalization}

It has been found that effective overburden stress can profoundly influence CPT measurements (Olsen and Mitchell, 1995). This stress effect is typically accounted for by normalizing the tip resistance for the effective overburden to a reference stress level of one atmosphere. A complete discussion of normalization for effective overburden stress can be found in Moss et al. (2004). In that paper cavity expansion methods were used to bolster previously reported field and laboratory results for determining the appropriate level of normalization based on the measured tip resistance and friction ratio. The discussion in this paper is limited, for brevity, to the application of the proposed normalization technique.

Figure 3 shows normalization exponent curves as a function of friction ratio and tip resistance. These curves define the exponent used to normalize the tip resistance for a given level of overburden stress, using the following equation,

$q_{c, 1}=C_{q} \cdot q_{c} \quad$ where $C_{q}=\left(\frac{P_{a}}{\sigma_{v}^{\prime}}\right)^{c}$

In Equation 4; $q_{c, l}$ is the normalized tip resistance (MPa), $C_{q}$ is the tip normalization factor, $q_{c}$ is the raw tip resistance (MPa), $P_{a}$ is the reference stress in compatible units, $\sigma_{v}$ ' 
is the effective overburden stress $(\mathrm{kPa})$, and $c$ is the normalization exponent. The normalization exponent curves in Figure 3 can be approximated by the iterative equation;

$$
\begin{aligned}
& c=f_{1} \cdot\left(\frac{R_{f}}{f_{3}}\right)^{f_{2}} \\
& \text { where } f_{1}=x_{1} \cdot q_{c}{ }^{x_{2}} \\
& f_{2}=-\left(y_{1} \cdot q_{c}{ }^{y_{2}}+y_{3}\right) \\
& f_{3}=a b s(\log (10+q c))^{z 1}
\end{aligned}
$$

In Equation 5; $c$ is the tip normalization exponent, $q_{c}$ the raw tip resistance (MPa), $R_{f}$ the friction ratio (\%), and $f_{1}, f_{2}, f_{3}, x_{1}, x_{2}, y_{1}, y_{1}, y_{3}$, and $z_{1}$ parameters of the equation. To normalize the tip appropriately, an iterative procedure is necessary. The iterative procedure involves the following steps;

1) An initial estimate of the normalization exponent is found using raw tip measurements, friction ratio, and Figure 3 or Equation 5,

2) The tip is then normalized using Equation 4 (note: friction ratio will not change when tip and sleeve are normalized equivalently),

3) A revised estimate of the normalization exponent is found using the normalized tip resistance and Figure 3 or Equation 5, which is compared to the initial normalization exponent estimate,

4) The procedure is repeated until an acceptable convergence tolerance is achieved. This process usually requires only two iterations to converge for most soils. It is recommended that the tip and sleeve be normalized equivalently.

\section{Magnitude Correlated Duration Weighting Factor $\left(D W F_{M}\right)$}

All results presented in this study include the correction of equivalent uniform cyclic stress ratio $\left(C S R\right.$ ) for duration (or number of equivalent cycles) to $C S R^{*}$, representing the $C S R$ for a duration typical of an "average" event of $M_{W}=7.5$. This was done by means of a magnitude-correlated duration weighting factor $\left(D W F_{M}\right)$;

$$
C S R^{*}=C S R_{M w=7.5}=\frac{C S R_{M w=?}}{D W F_{M_{w}}}
$$

This duration weighting factor is somewhat controversial, and has previously been developed using different approaches (cyclic laboratory testing and/or field case history data) by a number of investigators. Cetin et al. (2004), regressed the $D W F_{M}$ from an SPT-based liquefaction database which included events covering a wide spectrum of moment magnitudes. These results were found to be in good agreement with previously published lower-bound results by Youd et al., (2001), and also consistent with laboratory results published by Idriss (1999) and Liu et al. (2001). This CPT-based study was lacking a wide enough magnitude spectrum to discern accurately the $D W F_{M}$ in a similar manner, therefore the Cetin et al., (2004) $D W F_{M}$ results were used in this study. The recommended $D W F_{M}$ can be represented by the equation, 
$D W F_{M}=17.84 \cdot M_{w}^{-1.43}$

Equation 7 is valid for moment magnitudes from 5.5 to 8.5.

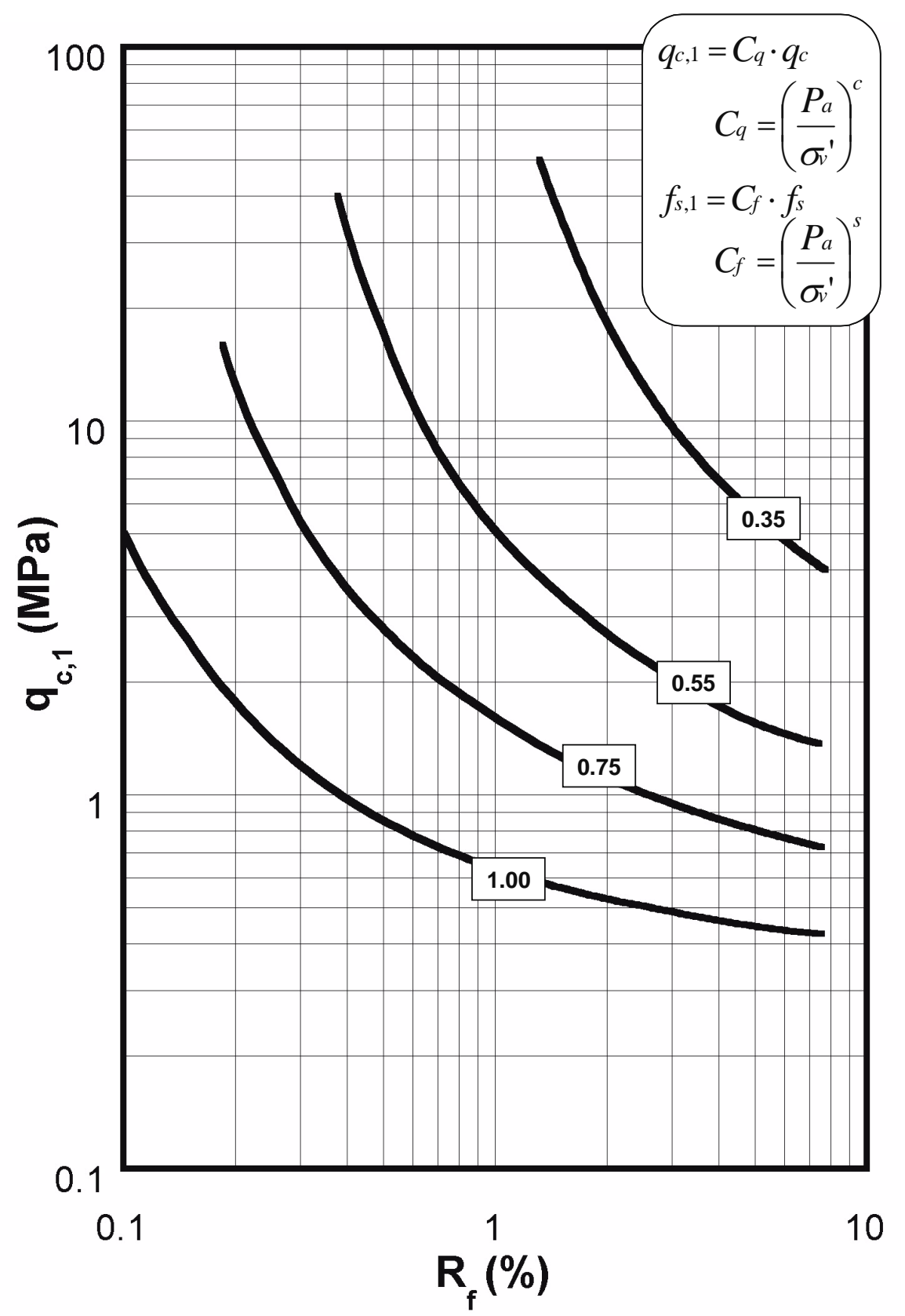

Figure 3. Proposed tip normalization exponent curves. Equation 5 can be used to calculate the normalization exponent, $c$, in the iterative normalization procedure. It is recommend that tip and sleeve resistance be normalized equivalently $(s=c)$. From Moss, Seed, and Olsen (2004). 
Non-linear shear mass participation factor $\left(r_{d}\right)$

The nonlinear shear mass participation factor $\left(r_{d}\right)$ accounts for nonlinear response within a soil column. It reduces the peak ground acceleration from the surface to reflect the ground acceleration that is experienced at the critical depth. This factor, previously proposed by various researchers, has been reassessed by Cetin et al. (2004) using ground response analyses. In this work, 2,153 site response analyses were run using 50 sites and 42 ground motions creating a comprehensive suite of motions and soil profiles. The results of those analyses provided ample information to perform statistical analysis on the median $r_{d}$ for a given depth, peak ground acceleration, and moment magnitude. The variance was estimated from the dispersion of these simulations. The median $r_{d}$ results can be represented by the following equations,

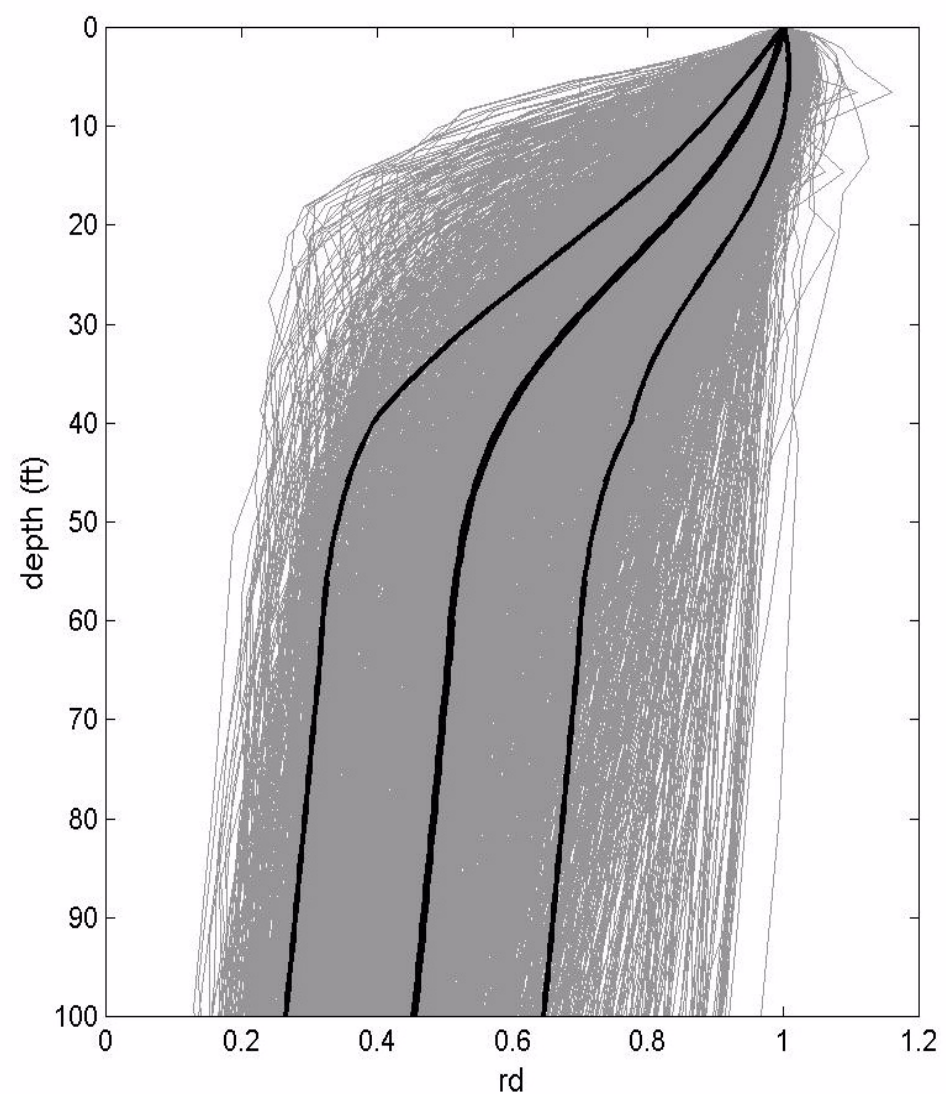

Figure 4. Mean and +1 Standard Deviation $r_{d}$ Values for the 2,153 Cases Analyzed, from Seed et al. (2004).

For $d<20$ meters,

$r_{d}\left(d, M_{w}, a_{\max }\right)=\frac{\left[1+\frac{-9.147-4.173 \cdot a_{\max }+0.652 \cdot M_{w}}{10.567+0.089 \cdot e^{0.089 \cdot\left(-d \cdot 3.28-7.760 \cdot a_{\max }+78.576\right)}}\right]}{\left[1+\frac{-9.147-4.173 \cdot P G A+0.652 \cdot M_{w}}{10.567+0.089 \cdot e^{0.089 \cdot\left(-7.760 \cdot a_{\max }+78.576\right)}}\right]}$

And for $d \geq 20$ meters,

$r_{d}\left(d, M_{w}, a_{\max }\right)=\frac{\left[1+\frac{-9.147-4.173 \cdot a_{\max }+0.652 \cdot M_{w}}{10.567+0.089 \cdot e^{0.089 \cdot\left(-d \cdot 3.28-7.760 \cdot a_{\max }+78.576\right)}}\right]}{\left[1+\frac{-9.147-4.173 \cdot a_{\max }+0.652 \cdot M_{w}}{10.567+0.089 \cdot e^{0.089 \cdot\left(-7.760 \cdot a_{\max }+78.576\right)}}\right]}$

In Equations 8 and $9 ; d$ is depth in meters to the midpoint of the critical layer, $M_{w}$ is moment magnitude, $a_{\max }$ is peak ground acceleration in units of gravity. 


\section{Correlation}

Figure 5 presents one view of the new recommended correlation, in this case a plot of contours of probability of liquefaction (for $P_{L}=5 \%, 20 \%, 50 \%, 80 \%$, and $95 \%$ ) as a function of equivalent uniform cyclic stress ratio $\left(C S R^{*}\right)$ and modified normalized CPT tip resistance $\left(q_{c, 1, m o d}\right)$. In this figure, equivalent uniform $C S R$ has been corrected for duration effects based on the magnitude correlated duration weighting factor $\left(D W F_{M}\right)$. In Figure 5, the solid dots represent the centroids of probabilistic distributions of the individual case histories for cases wherein liquefaction was judged to have been "triggered" and open circles represent centroids of distributions of field cases wherein liquefaction did not occur. These distributions quantify each individual field case history and its distributed variance. The horizontal axis of Figure 5 represents modification of normalized CPT tip resistances ( $q_{c, 1}$ values) for the frictional effects of apparent fines content and character. To account for the systematic suppression of liquefiability with increased friction ratio, values of $q_{c, 1}$ are adjusted by,

$$
\begin{aligned}
& q_{c, 1, \text { mod }}=q_{c, 1}+\Delta q_{c} \\
& \text { where } \Delta q_{c}=x_{1} \cdot \ln (C S R)+x_{2} \\
& \text { and } x_{1}=0.38 \cdot\left(R_{f}\right)-0.19 \text { and } x_{2}=1.46 \cdot\left(R_{f}\right)-0.73
\end{aligned}
$$

In Equation 10; $q_{c, 1}$ is in $\mathrm{MPa}, R_{f}$ in percent (\%), and the bounds of $\Delta q_{c}$ are from $R_{f}=0.5$ to 5.0, where $\Delta q_{c}=0$ when $R_{f} \leq 0.5, \Delta q_{c}$ reaches its maximum at $R_{f}=5.0$, and no data exists for $R_{f}>5.0$. This term was regressed from the liquefaction database and represents the change in liquefiability correlated to the change in friction ratio, as a function of CSR.

Figure 6 presents an alternate, deterministic, view of the new correlation. In this case contours of $P_{L}=15 \%$ are shown for three different values of mean $\Delta q_{c}$ spanning the full available range of $\Delta q_{c}$. The curves also represent approximate contours of equal friction ratio.

For exact parameter estimation (assuming mean values), the following equation can be used to calculate the probability of liquefaction,

$$
P_{L}=\Phi\left(-\frac{\left(\begin{array}{l}
q_{c, 1}{ }^{1.045}+q_{c, 1}\left(0.110 \cdot R_{f}\right)+\left(0.001 \cdot R_{f}\right)+c\left(1+0.850 \cdot R_{f}\right)-7.177 \cdot \\
\ln (C S R)-0.848 \cdot \ln \left(M_{w}\right)-0.002 \cdot \ln \left(\sigma_{v}{ }^{\prime}\right)-20.923
\end{array}\right)}{1.632}\right)
$$

where; $q_{c, 1}$ is the normalized tip resistance (MPa), $R_{f}$ is the friction ratio $(\%), c$ is the normalization exponent, $C S R$ is the equivalent uniform cyclic stress ratio, $\sigma_{v}$ ' is the effective overburden stress $(\mathrm{kPa})$, and $\Phi$ and the cumulative normal distribution which can be calculated using the $\operatorname{NORM}\left(P_{L}, 0,1\right)$ function in Excel. The cyclic resistance ratio for a given probability of liquefaction can be calculated from, 
$C R R=\exp \left(\frac{\left(\begin{array}{l}q_{c, 1}{ }^{1.045}+q_{c, 1}\left(0.110 \cdot R_{f}\right)+\left(0.001 \cdot R_{f}\right)+c\left(1+0.850 \cdot R_{f}\right) \\ -0.848 \cdot \ln \left(M_{w}\right)-0.002 \cdot \ln \left(\sigma_{v}{ }^{\prime}\right)-20.923+1.632 \cdot \Phi^{-1}\left(P_{L}\right)\end{array}\right)}{7.177}\right)$

where the inverse cumulative normal distribution function, $\Phi^{-1}\left(P_{L}\right)$, can be calculated using the $\operatorname{NORMINV}\left(P_{L}, 0,1\right)$ function in Excel. Comparison of the results with previous deterministic and probabilistic results can be found in Moss et al. (2004). Note that Equation 12 produces results for the input magnitude $\left(C R R_{M w=?}\right)$, whereas Figures 5 and 6 produce results for a mean magnitude of $7.5\left(C S R^{*}\right)$.

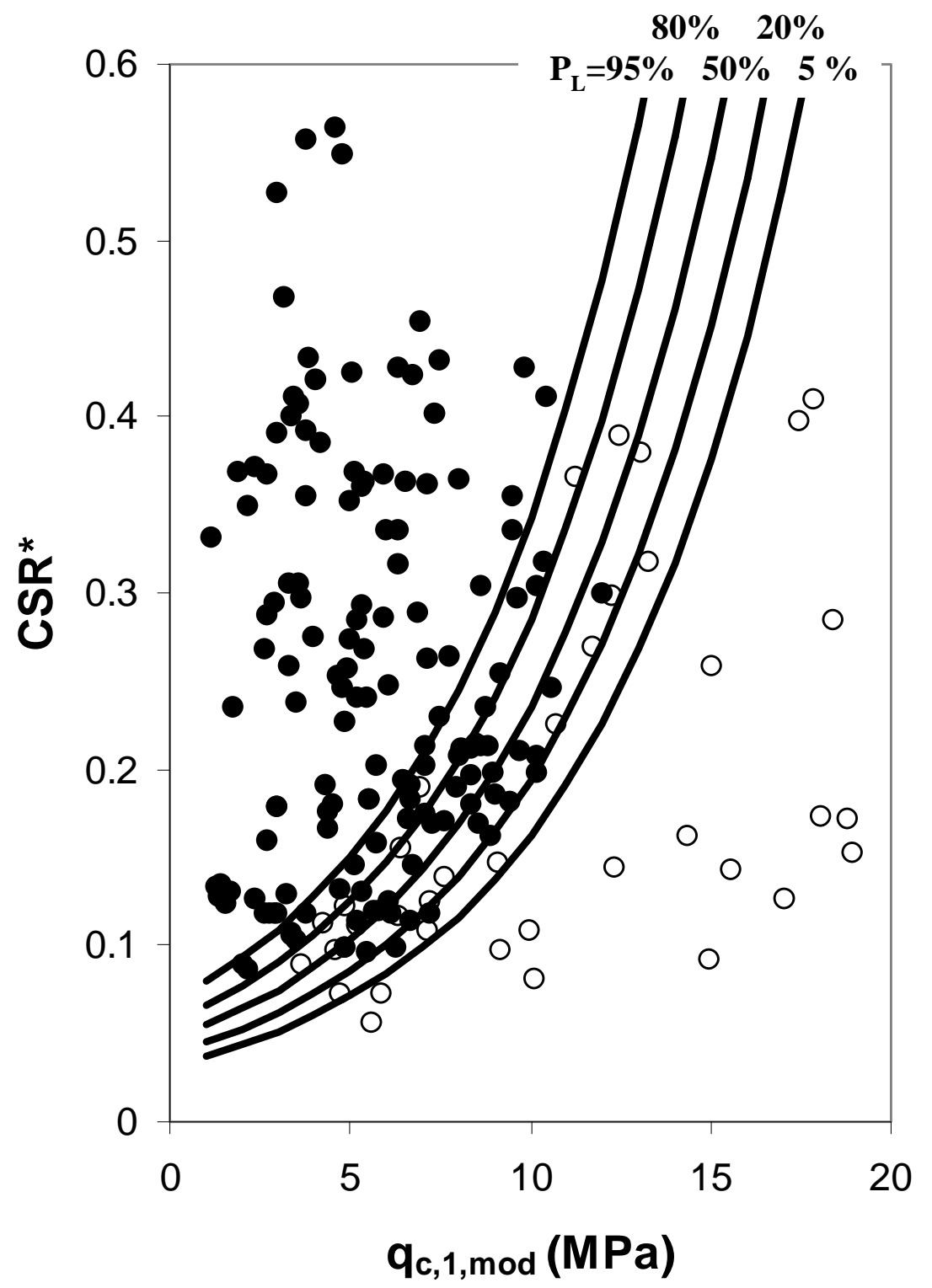

Figure 5. Contours of $5 \%, 20 \%, 50 \%, 80 \%$ and $95 \%$ probability of liquefaction as a function of equivalent uniform cyclic stress ratio and "fines"-modified CPT tip resistance for $M_{w}=7.5, \sigma_{v}$ ' = 1 atmosphere, from Moss et al., (2004). 
The liquefaction triggering results presented in this paper can be used in forward analyses either in a probabilistic or deterministic manner. Normalized tip resistance $\left(q_{c, 1}\right)$ and the normalization exponent $(c)$ were incorporated into the limit-state function for the Bayesian updating and reliability analysis. This resulted in a complete assessment of the influence of effective overburden on CPT measurements and liquefaction. Therefore, using the recommended iterative normalization scheme obviates the need for subsequent $\mathrm{K}_{\sigma}$ corrections commonly used in liquefaction analysis.

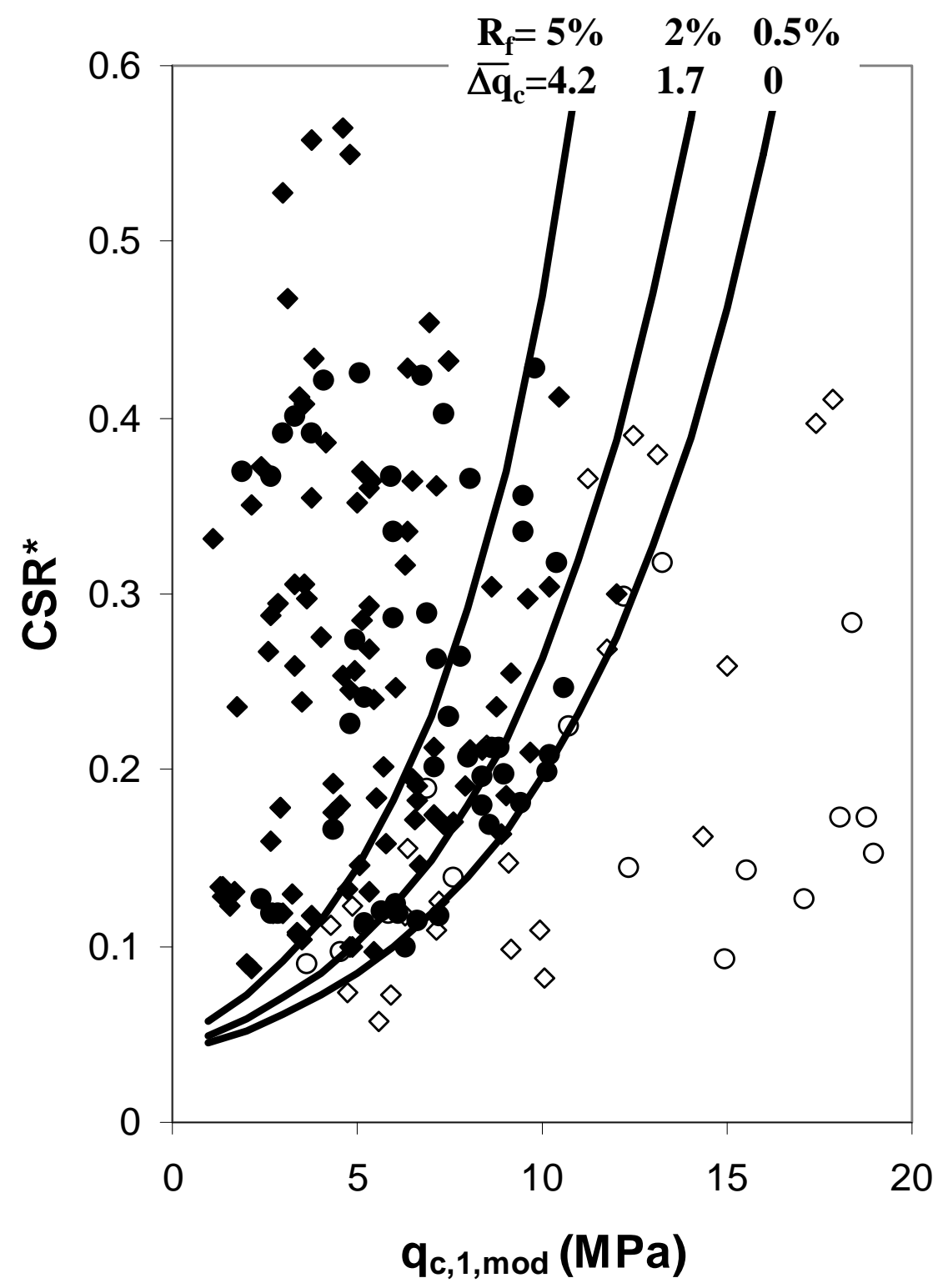

Figure 6. Constant friction ratio triggering curves all shown for $P_{L}=15 \%$. The round data points indicate "clean" sands $\left(R_{\mathrm{f}} \leq \mathbf{0 . 5 \%}\right)$ and the diamond data points indicate soils of higher "fines" $\left(R_{\mathrm{f}}>0.5 \%\right)$, for $M_{w}=7.5, \sigma_{v}{ }^{\prime}=1$ atmosphere, from Moss et al., (2004). 


\section{Summary}

Presented is a synopsis of the recent CPT-based liquefaction triggering correlations as presented in Moss et al. (2004). These correlations treat the problem of liquefaction triggering as inherently uncertain, and strive to fully capture all forms of uncertainty. The results are presented probabilistically for performance-based engineering applications. Discussed are the steps and procedures necessary for calculating the probability of liquefaction, including; screening procedures for liquefiable material, calculation of the nonlinear shear mass participation factor $\left(r_{d}\right)$, normalization of the CPT measurements for effective overburden, and corrections of $C S R$ for magnitude correlated duration $\left(D W F_{M}\right)$. The goal of this work was to provide as unbiased an assessment of liquefaction triggering as possible based on the CPT.

\section{Acknowledgements}

Financial support was provided by the California Department of Transportation (CalTrans), the California Energy Commission (CEC), and Pacific Gas and Electric Company (PG\&E) through the Pacific Earthquake Engineering Research (PEER) Center's Lifelines Program, Task 3D02. This support is greatly appreciated.

\section{References}

Andrianopoulos, K. I., Bouckovalas, G. D., and Papadimitriou, A. G. (2001). "A Critical State Evaluation of Fines Effect on Liquefaction Potential." Proc. 4th Int. Conf. on Recent Advances in Geotechnical Earthquake Engineering and Soil Dynamics Paper No. 4.06.

Andrews, D.C.A. and Martin, G.R. (2000) “Criteria for Liquefaction of Silty Soils." Proc.12 ${ }^{\text {th }}$ World Conf. Earthquake Engineering, Auckland, NZ, Paper 0312.

Cetin, K. O., Seed, R. B., Der Kiureghian, A., Tokimatsu, K., Harder, L. F. Jr, Kayen, R. E., and Moss, R. E. S. (2004). "SPT-Based Probabilistic and Deterministic Assessment of Seismic Soil Liquefaction Potential." Journal of Geotechnical and Environmental Engineering, ASCE, accepted in-press.

Cetin, K.O., Der Kiureghian, A., and Seed, R.B. (2002) "Probabilistic Models for the Initiation of Seismic Soil Liquefaction." Structural Safety, 24, pp. 67-82.

Guo, T. and Prakash, S. (1999). "Liquefaction of Silts and Silt-Clay Mixtures." Journal of Geotechnical and Geoenvironmental Engineering, 125(9), 706-710.

Idriss, I. M. (1999). "An update to the Seed-Idress simplified procedure for evaluating liquefaction potential." Presentation notes, Workshop, new approaches to liquefaction analysis, Transprotation Research Board, Washington D.C.

Juang, C. H., Yuan, H., Lee, D. H., and Lin, P. S. (2003). "Simplified Cone Penetration Test-based Method for Evaluating Liquefaction Resistance of Soils." Journal of Geotechnical and Geoenvironmental Engineering, 129(1), 66-80.

Liu, A. H., Stewart, J. P., Abrahamson, N. A., Moriwaki, Y. (2001). "Equivalent Number of Uniform Stress Cycles for Soil Liquefaction Analysis." Journal of Geotechnical and Geoenvironmental Engineering, 127(12), 1017-1026

Mitchell, J. K. and Tseng, D. J. (1990). "Assessment of Liquefaction Potential by Cone Penetration Resistance." Proceedings from the H. Bolton Seed Memorial Symposium Duncan, J. M. BiTech, Vancouver, B. C., 335-350.

Moss, R.E.S., Seed, R.B., Kayen, R.E., Stewart, J.P., Youd, T.L., and Tokimatsu, K. (2004) “CPT-based Probabilistic Liquefaction Triggering Assessment." Journal of Geotechnical and Geoenvironmental Engineering, submitted in-review.

Moss, R.E.S., Seed, R.B., and Olsen, R.S. (2004). “Normalizing the CPT for Overburden Stress.” Journal of Geotechnical and Geoenvironmental Engineering, submitted in-review. 
Moss, R. E. S., Cetin, K. O., and Seed, R. B. (2003) "Seismic Liquefaction Triggering Correlations within a Bayesian Framework ." $9^{\text {th }}$ International Conf. Application of Statistic and Probability in Civil Engineering.

Moss, R.E.S. (2003) "CPT-Based Probabilistic Assessment of Seismic Soil Liquefaction Initiation." Dissertation in partial fulfillment of the requirements for the degree of Doctor of Philosophy, University of California, Berkeley.

Moss, R.E.S., Seed, R.B., Kayen, R.E., Stewart, J.P., Youd, T.L., and Tokimatsu, K. (2003) "Field Case Histories for CPT-Based In Situ Liquefaction Potential Evaluation." Geoengineering Research Report No.UCB/GE-2003/04.

Olsen, R. S. and Mitchell, J. K. (1995b). "CPT Stress Normalization and Prediction of Soil Classification." International Symposium on Cone Penetration Testing, CPT 95 Linkoping, Sweden, 257-262.

Perlea, V.G. (2000) "Liquefaction of Cohesive Soils." Soil Dynamics and Liquefaction 2000, ASCE Geotechnical Specialty Publication No. 107, 58-75.

Polito, C. (2001) "Plasticity Based Liquefaction Criteria." Proc. $4^{\text {th }}$ International Conf. Recent Advances in Geotechnical Earthquake Engineering and Soil Dynamics, Paper No. 1.33.

Robertson, P. K. and Campanella, R. G. (1985). "Liquefaction Potential of Sands Using the CPT." Journal of Geotechnical Engineering, 111(3), 384-403.

Robertson, P. K. and Wride, C. E. (1998). "Evaluating Cyclic Liquefaction Potential Using the Cone Penetration Test." Canadian Geotechnical Journal, 35(3), 442-459.

Sancio, R. B., Bray, J. D., Riemer, M. F., and Durgunoglu, T. (2003). "An Assessment of the Liquefaction Susceptibility of Adapazari Silt." 2003 Pacific Conf. Earthquake Engineering, New Zealand.

Shibata, T. and Teparaska, W. (1988). "Evaluation of Liquefaction Potential of Soils Using Cone Penetration Testing." Soils and Foundations, Journal of the Japanese Society of Soil Mechanics and Foundation Engineering, 28(2), 49-60.

Seed, H. B. and Idriss, I. M. (1971). "Simplified Procedure for Evaluating Soil Liquefaction Potential." Journal of the Soil Mechanics and Foundations Division, ASCE, 97(SM 9), 1249-1273.

Seed, H.B., Idriss, I.M. (1982). Ground Motion and Soil Liquefaction During Earthquakes. Monograph, Earthquake Engineering Research Institute, Oakland.

Seed, H. B. and De Alba, P. (1986). "Use of SPT and CPT Tests for Evaluating the Liquefaction Resistance of Sands.", 281-302.

Seed, R.B., Cetin, K.O., Moss, R.E.S., Kammerer, A., Wu, J., Pestana, J. and Riemer, M., Sancio, R.B., Bray, J.D., Kayen, R.E., and Faris, A. (2003) "Recent Advances in Soil Liquefaction Engineering: A Unified and Consistent Framework." Earthquake Engineering Research Center Report No. EERC 2003-06. http://eerc.berkeley.edu/reports/.

Stark, T. D. and Olson, S. M. (1995). "Liquefaction Resistance Using CPT and Field Case Histories." Journal of Geotechnical Engineering, 121(12), 856-869.

Suzuki, Y., Koyamada, K., Tokimatsu, K., Taya, Y., and Kubota, Y. (1995). "Empirical Correlation of Soil Liquefaction Based on Cone Penetration Test." First International Conference on Geotechnical Earthquake Engineering Ishihara, K. A. A. Balkema, Rotterdam, 369-374.

Toprak, S., Holzer, T. L., Bennett, M. J., and Tinsley, J. C. I. (1999). "CPT- and SPT-based Probabilistic Assessment of Liquefaction." Proc., 7th U.S.-Japan Workshop on Earthquake Resistant Design of Lifeline Facilities and Countermeasures Against Liquefaction MCEER, Seattle, WA, 69-86.

Wang, W. (1979). "Some Findings in Soil Liquefaction." Research Report, Water Conservancy and Hydroelectric Power Scientific Research Institute, Beijing.

Yamamuro, J. A. and Lade, P. (1998). "Steady-State Concepts and Static Liquefaction of Silty Sands." Journal of Geotechnical and Geoenvironmental Engineering, 124(9), 868-877.

Youd, T.L., I. M. Idriss, Ronald D. Andrus, Ignacio Arango, Gonzalo Castro, John T. Christian, Richardo Dobry, W. D. Liam Finn, Leslie F. Harder Jr., Mary Ellen Hynes, Kenji Ishihara, Joseph P. Koester, Sam S. C. Liao, William F. Marcuson III, Geoffrey R. Martin, James K. Mitchell, Yoshiharu Moriwaki, Maurice S. Power, Peter K. Robertson, Raymond B. Seed, and Kenneth H. Stokoe II. (2001) "Liquefaction Resistance of Soils: Summary Report from the 1996 NCEER and 1998 NCEER/NSF Workshops on Evaluation of Liquefaction Resistance of Soils." Journal of Geotechnical and Geoenvironmental Engineering, 124(10), 817-833.

Youd, T.L. and Gilstrap, S.D. (1999). "Liquefaction and Deformation of Silty and Fine-Grained Soils." Proc. $2^{\text {nd }}$ International Conf. Earthquake Geotechnical Engineering, Vol. 3, 1013-1020. 